www.jmscr.igmpublication.org

Impact Factor 5.84

Index Copernicus Value: 83.27

ISSN (e)-2347-176x ISSN (p) 2455-0450

crossref DOI: _https://dx.doi.org/10.18535/jmscr/v5i6.182

Journal Of Medical Science And Clinical Research

\title{
The Role of Renal Resistive Index in Assessing the Early Renal Dysfunction
} of Cirrhosis

Authors

\author{
Dr Nivethitha Karthika L ${ }^{1}$, Dr Riyaz Ahmed $S^{2}$, Dr Samai $\mathbf{P}^{3}$, Dr Akshiitha Ramesh ${ }^{4}$, \\ Dr Manivel ${ }^{5}$, Dr Seena $\mathbf{C R}^{6}$, Dr Kulasekaran $\mathbf{N}^{7}$ \\ ${ }^{1}$ Senior Resident, Department of General Medicine, Saveetha Medical College and Hospital \\ ${ }^{2,3,4}$ Post Graduate Resident, Department of Radiodiagnosis, Saveetha Medical College and Hospital \\ ${ }^{5}$ Professor, Department of General Medicine, Saveetha Medical College and Hospital \\ ${ }^{6}$ Professor, Department of Radiodiagnosis, Saveetha Medical College and Hospital \\ ${ }^{7}$ Head of the Department of Radiodiagnosis, Saveetha Medical College and Hospital \\ Corresponding Author
}

Dr Nivethitha Karthika L

Senior Resident, Department of General Medicine, Saveetha Medical College and Hospital, Saveetha Nagar,

Thandalam, Chennai - 602105

\begin{abstract}
Background: Hyperdynamic circulatory state in cirrhosis leads to splanchnic vasodilatation and renal vasoconstriction in that leads to the development of hepatorenal syndrome (HRS).

Aim: To measure the intrarenal resistive index in patients with and without ascites and compare the value of RI with Child Pugh and MELD scoring systems.

Methods: 100 patients with cirrhosis liver were selected for the study. Bilirubin, INR and serum creatinine were measured and patients were subjected to sonographic evaluation of abdomen followed by Doppler Ultrasound of both kidneys and RI values were obtained. Linear regression analysis was used between RI and MELD that showed significant correlation.

Results: 71 patients had RI $>0.7$ (0.7 kept as cut-off value) 29 patients had $R I<0.7$

Patients with severe ascites had more RI than the patients with absent or mild to moderate ascites and had significant comparability with CTP scoring and MELD scoring systems.

Conclusion: Value of RI was higher in patients with cirrhosis and comparable prognostic value with MELD and CTP scoring system.

Key Words: Hepatorenal syndrome, cirrhosis, MELD, CTP, Child Pugh Score, Renal resistive index.
\end{abstract}

\section{INTRODUCTION}

Cirrhosis of liver is the tenth leading cause of death in India and a major cause of disease burden among the population. ${ }^{1}$ The expenditure in treatment not only burns out the country's economic resources but also a major cause of sickness absenteeism leading to man days losses.
The disease course is further altered by the development of numerable complications like varices, hepatic encephalopathy, coagulopathy, hepatopulmonary syndrome, cirrhotic cardiomyopathy, hepatorenal syndrome that carries a grave prognosis. ${ }^{2}$ 
Among the various complications of advanced cirrhosis, development of hepatorenal syndrome has a devastating course and outcome in cirrhotic patients. ${ }^{3}$ HRS is usually an extended spectrum of prerenal azotaemia and therefore is potentially reversible.

But after the evolution of the disease, the median survival is only 2 weeks without liver transplantation or management with vasoconstrictors. HRS is a part of events occurring in the background of cirrhosis with PHT or acute liver injury.

Usually HRS can be diagnosed only after the rise in blood urea nitrogen and serum creatinine. By then the disease has progressed so that it is no longer reversible and has a poor outcome. But the disease can be predicted in advance by the estimation of renal resistive index( $\mathrm{RI})$ that increases before a considerable period of time by Doppler ultrasound and so measures can be implemented to prevent the disease progression by avoiding the excess use of diuretics and nephrotoxic agents, avoiding large volume paracentesis. ${ }^{4}$

RI is routinely used to diagnose transplant rejection or renal artery stenosis ${ }^{5,6}$. But here in the current study, we calculated the intrarenal RI in patients with liver cirrhosis and compared its prognostic impact with those of the MELD and the Child-Pugh scores.

\section{AIMS AND OBJECTIVES}

To measure the intrarenal resistive index in patients with liver cirrhosis and estimate the development of renal vasoconstriction before overt hepatorenal syndrome develops in cirrhotic patients with and without ascites. ${ }^{7}$ This study also compares the resistive index with MELD and Child Pugh scoring system.

\section{SUBJECTS AND METHODS STUDY SUBJECTS}

Adult patients over 18 years diagnosedto have cirrhosis of liver were selected. 100 such patientsproven to havecirrhosis liver by clinical, laboratory and sonographic evidence with normal renal functions were taken up, screened and enrolled in the study. Patients with diabetic kidney disease, gastrointestinal bleeding, spontaneous bacterial peritonitis, overt hepatorenal syndrome and infections were excluded from the study.Informed consent was obtained from all patients before their inclusion.

\section{STUDY DESIGN}

Data was collected in a pretested proforma from eligible patients. 100 patients were selected on the basis of simple random sampling. They were subjected to detailed history taking and clinical examination. Laboratory tests for liver and renal function were performed on each patient and clinical parameters, such as blood pressure, heart rate were measured. Hepatic encephalopathy was clinically assessed and classified according to the West Haven scale (0-4) .Ascites was graded as absent, mild to moderate and severe based on sonography.

Patients who were enrolled in the study were subjected to sonographic evaluation of the liver and the kidneys and the Doppler ultrasound was done on each kidneys. All patients were made to fast for at least 6 hours prior to the examination. All examinations were done using $5-12 \mathrm{MHz}$ transducer. Patients were made to lie in supine position, right lateral and left lateral position.

Abdominal aorta was identified and the ostium of right and left main renal arteries were identified and the corresponding PSV and EDV were taken. Then the PSV and EDV were taken from the renal arteries at the hilum, lobar, lobular and arcuate arteries. Then mean RI was calculated for each right and left kidney and finally mean of the two values was calculated as the RI by the formula

\section{RI - (PSV- EDV/PSV)}

RRI value of more than 0.7 was taken as the cut off

\section{STATISTICAL ANALYSIS}

All data were expressed as means \pm standard deviations. Statistical analysis was performed using SPSS. Statistical significance was shown by the Chi-square test. Variables were considered to 
be significant if $\mathrm{p}<0.05$. Correlation and linearregression analysis were used for statistical analysis.

\section{RESULTS}

Out of 100 patients PHT was there in patients in $73(73 \%)$ patients and absent in 27(27\%) patients. According to CTP classification, 12 patients (12\%) were in class A, 34 patients (34\%) were in class B and 54 patients (54\%) were in class C. According to MELD score in under 9 therewere 2 patients (2\%), between10- 19 there were 63 patients(63\%), between 20-29 there 35 patients (35\%).

Resistive index was more than 0.7 for 71 patients (71\%) and less than 0.7 for 29 patients $(29 \%)$ The value of RI in patients for whom there was no ascites was ranging from 0.67 to 0.76 , mild to moderate ascites was 0.69 to 0.76 and for severe ascites was from 0.71 to 0.80 . So the RI was significantly higher in patients with severe ascites (FIGURE 1) In patients with PHT 93\% had RI more than 0.7 and $24.1 \%$ had $<0.7$. In patients without PHT $7 \%$ had had RI more than 0.7 and $75.9 \%$ patients had more 0.7.(FIGURE 2)This signifies that presence of portal hypertension increases the intrarenal resistance and hence leading to HRS.
Patients under CTP A class had RI ranging from 0.68 to 0.74 , CTP B class had the range from 0.67 to 0.78 and CTP C class had RI from 0.69 to 0.80.So the value was higher among patients under group $\mathrm{C}$ indicating as the severity disease increases RI also increases. RI less than 0.7 was seen in $31 \%$ in CPC A , 37.9\% in CPC B, 31\% in $\mathrm{CPC} \mathrm{C}$ and more than 0.7 seen in $4.2 \%$ in CPC A, $32.4 \%$ CPC B, $63.4 \%$ in CP C C (TABLE1, FIGURE 3)

Patients having a MELD scoring of $0-9$ have RI ranging from 0.68 to $0.68,10-29$ have RI ranging from 0.67 to 0.79 and $20-29$ have RI values from 0.70 to 0.80 . In our study RI values less than 0.7 was seen in $6.9 \%$ having score of $0-9$, in $86.2 \%$ having score of 10-19 and in 6.9\% having 20-29. RI values more than 0.7 was seen in $0 \%$ having score of $0-9$, in $53.5 \%$ having score of $10-19$, and in $46.5 \%$ having $20-29$.(TABLE 2,FIGURE 4)

There is a significant direct linear relationship between RI and MELD scores. Pearson correlation was 0.5748 that showed correlation between RI and MELD scores.(TABLE 3, FIGURE 5) Patients having higher resistive index had normal creatinine suggesting that normal value of creatinine underestimates the actual scenario in cirrhotic patients.

FIGURE 1: Representation of RI and Grading of Ascites

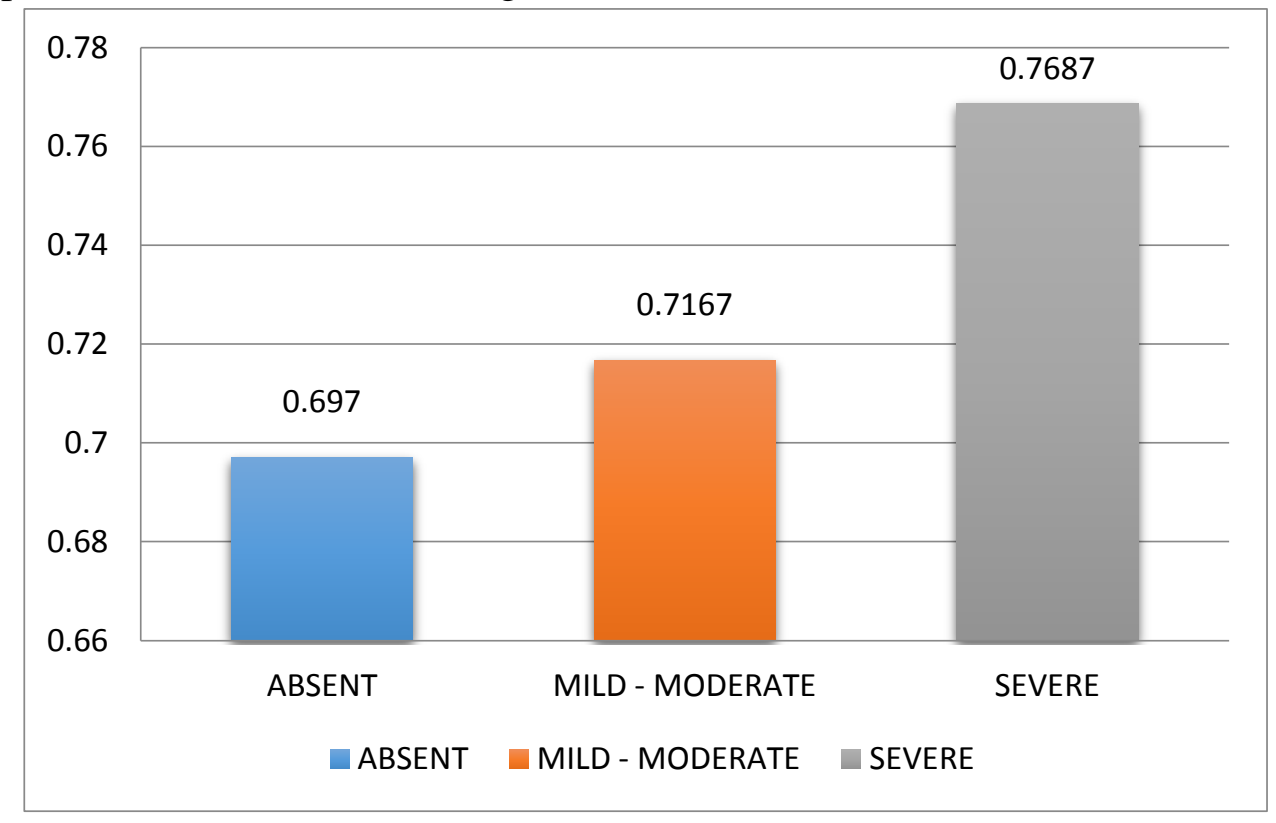




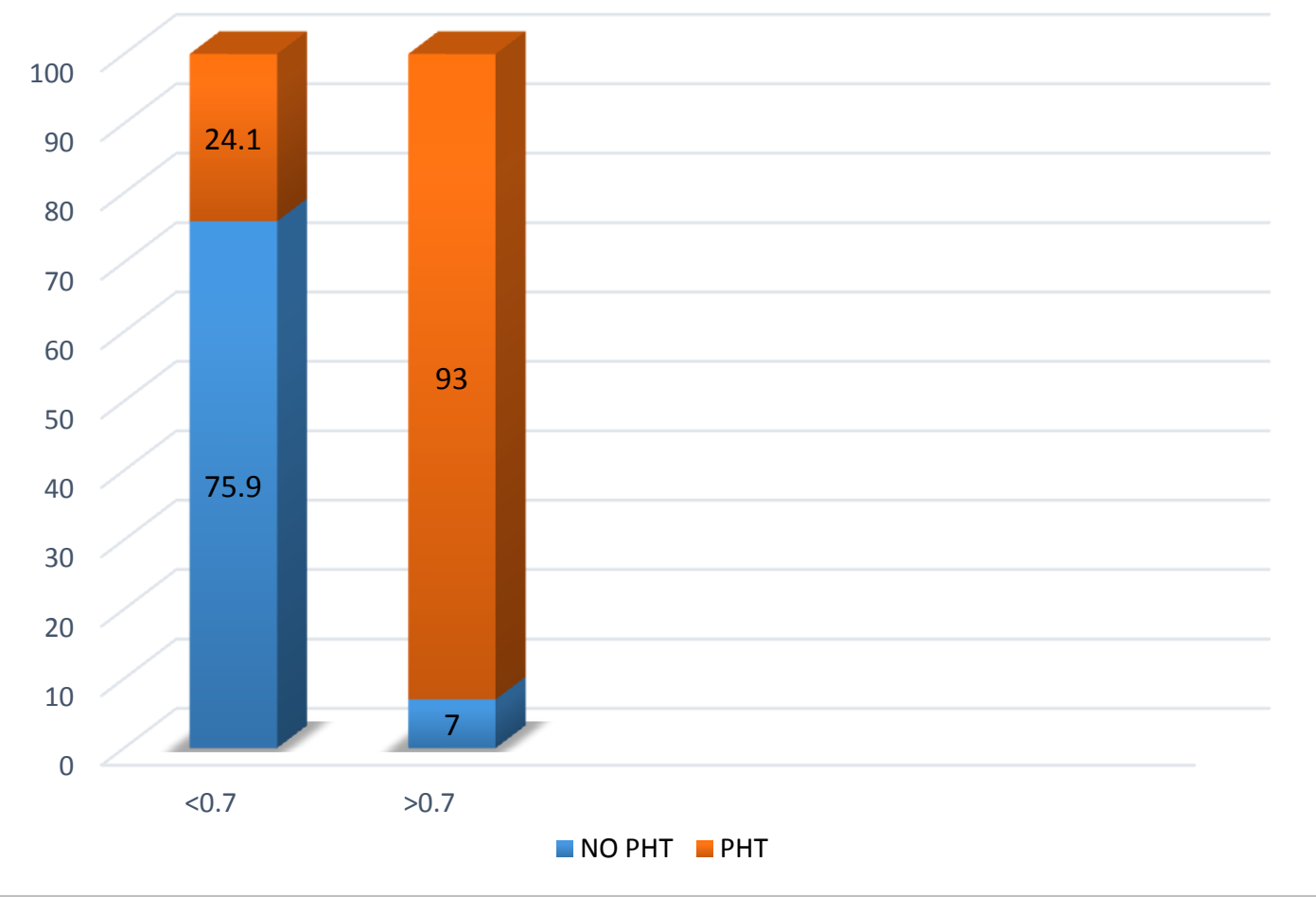

FIGURE 2: Representation of PHT with RI

TABLE 1: Cross Tabulation between CTP and RI

\begin{tabular}{|c|c|c|c|c|c|c|c|}
\hline & \multicolumn{2}{|c|}{$\begin{array}{l}\text { RELATIVE INDEX } \\
\text { SCORE }\end{array}$} & \multirow[t]{2}{*}{ Total } & \multirow{2}{*}{$\begin{array}{l}\text { Chi } \\
\text { square }\end{array}$} & \multirow{2}{*}{$P$ value } \\
\hline & & & $<=0.7$ & $>0.7$ & & & \\
\hline \multirow{6}{*}{ CTP Score } & & Count & 9 & 3 & 12 & \multirow{8}{*}{16.507} & \multirow{8}{*}{$\mathrm{P}<0.001$} \\
\hline & A & $\begin{array}{l}\% \text { within RELATIVE } \\
\text { INDEX SCORE }\end{array}$ & $31.00 \%$ & $4.20 \%$ & $12.00 \%$ & & \\
\hline & & Count & 11 & 23 & 34 & & \\
\hline & B & $\begin{array}{l}\% \text { within RELATIVE } \\
\text { INDEX SCORE }\end{array}$ & $37.90 \%$ & $32.40 \%$ & $34.00 \%$ & & \\
\hline & & Count & 9 & 45 & 54 & & \\
\hline & $\mathrm{C}$ & $\begin{array}{l}\% \text { within RELATIVE } \\
\text { INDEX SCORE }\end{array}$ & $31.00 \%$ & $63.40 \%$ & $54.00 \%$ & & \\
\hline \multirow{2}{*}{\multicolumn{2}{|c|}{ Total }} & Count & 29 & 71 & 100 & & \\
\hline & & $\begin{array}{l}\% \text { within RELATIVE } \\
\text { INDEX SCORE }\end{array}$ & $100.00 \%$ & $100.00 \%$ & $100.00 \%$ & & \\
\hline
\end{tabular}




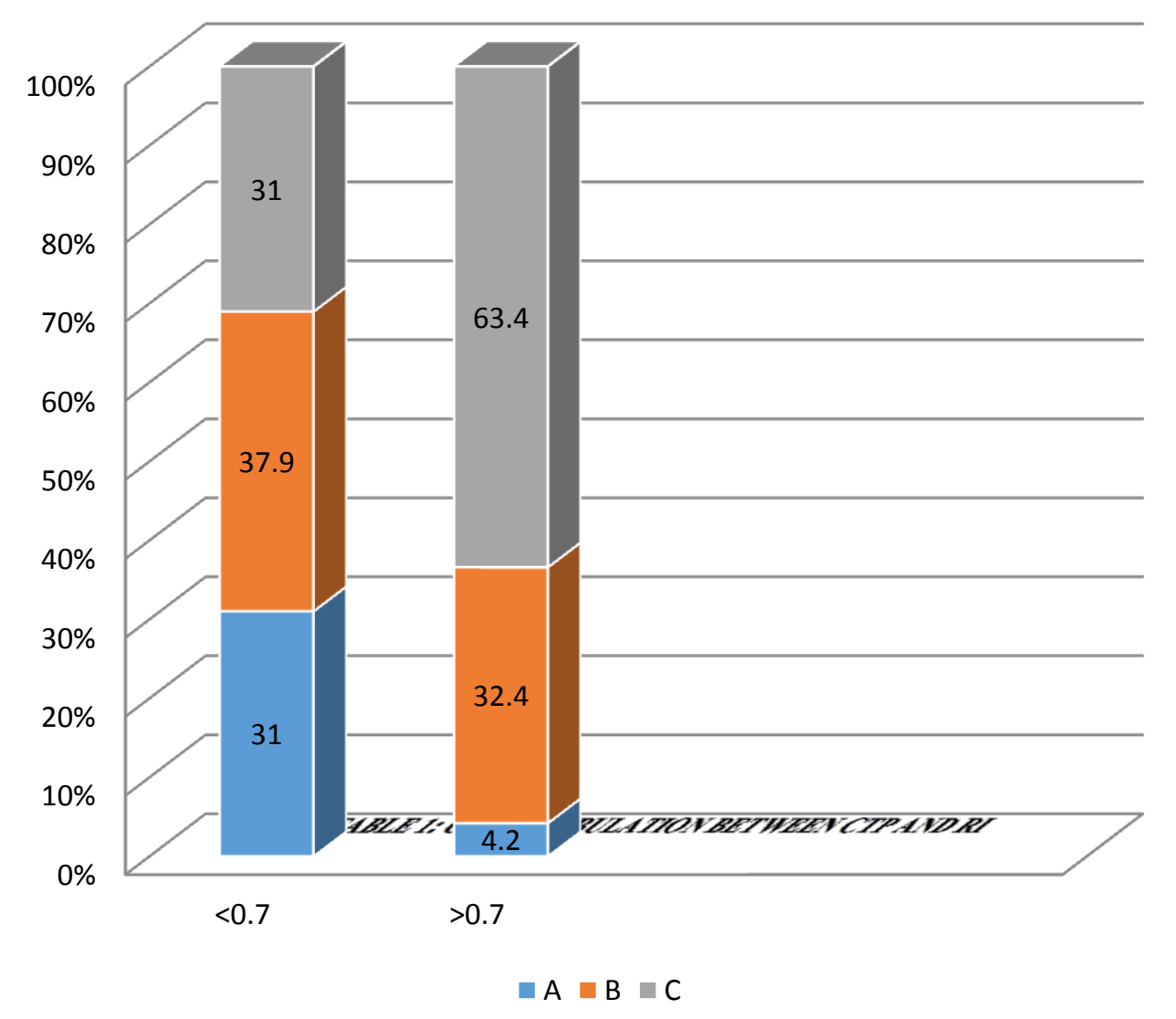

FIGURE 2: Graphic Representation between CTP and RI

TABLE3: Cross tabulation between RI and MELD

\begin{tabular}{|c|c|c|c|c|c|c|}
\hline \multicolumn{2}{|l|}{ MELD } & \multicolumn{2}{|c|}{$\begin{array}{l}\text { RELATIVE INDEX } \\
\text { SCORE }\end{array}$} & \multirow{3}{*}{$\begin{array}{c}\text { Total } \\
2 \\
\end{array}$} & \multirow{2}{*}{$\begin{array}{c}\text { CHI } \\
\text { SQUARE }\end{array}$} & \multirow{2}{*}{ P VALUE } \\
\hline \multirow[b]{3}{*}{$<9$} & & \multirow{3}{*}{$\begin{array}{c}<=\mathbf{0 . 7} \\
2 \\
6.90 \%\end{array}$} & \multirow{3}{*}{$\begin{array}{c}>\mathbf{0 . 7} \\
0 \\
0.00 \%\end{array}$} & & & \\
\hline & Count & & & & \multirow{8}{*}{17.605} & \multirow{8}{*}{$\mathrm{P}<0.001$} \\
\hline & $\begin{array}{l}\% \text { within RELATIVE } \\
\text { INDEX SCORE }\end{array}$ & & & $2.00 \%$ & & \\
\hline \multirow[b]{2}{*}{$10-19$} & Count & 25 & 38 & 63 & & \\
\hline & $\begin{array}{l}\% \text { within RELATIVE } \\
\text { INDEX SCORE }\end{array}$ & $86.20 \%$ & $53.50 \%$ & $63.00 \%$ & & \\
\hline \multirow[b]{2}{*}{$20-29$} & Count & 2 & 33 & 35 & & \\
\hline & $\begin{array}{l}\% \text { within RELATIVE } \\
\text { INDEX SCORE }\end{array}$ & $6.90 \%$ & $46.50 \%$ & $35.00 \%$ & & \\
\hline \multirow[b]{2}{*}{ Total } & Count & 29 & 71 & 100 & & \\
\hline & $\begin{array}{l}\% \text { within RELATIVE } \\
\text { INDEX SCORE }\end{array}$ & $100.00 \%$ & $100.00 \%$ & $100.00 \%$ & & \\
\hline
\end{tabular}




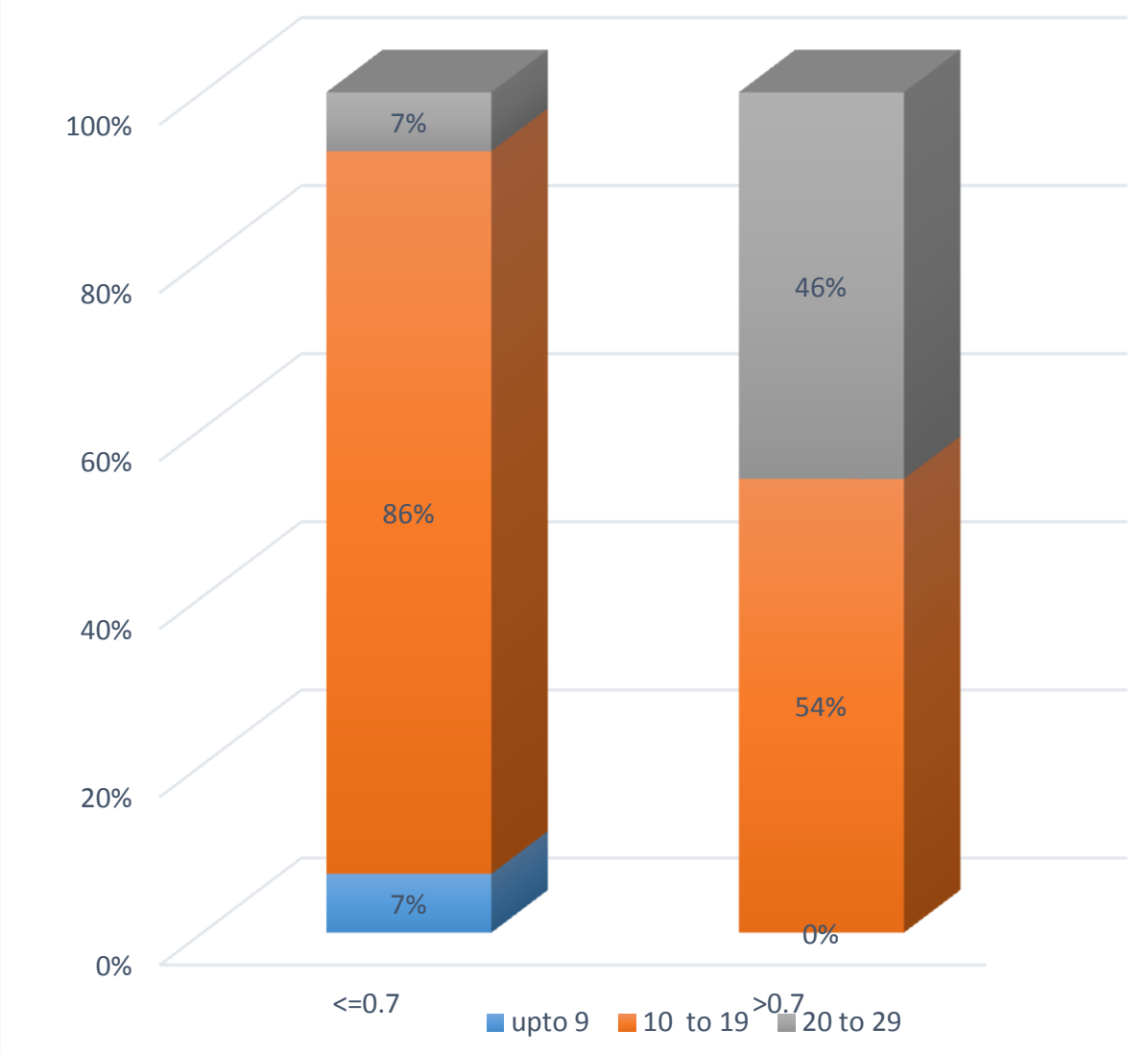

FIGURE 3: Graphic Representation between RI and MELD

FIGURE 4: Linear Regression Analysis between MELD and RI

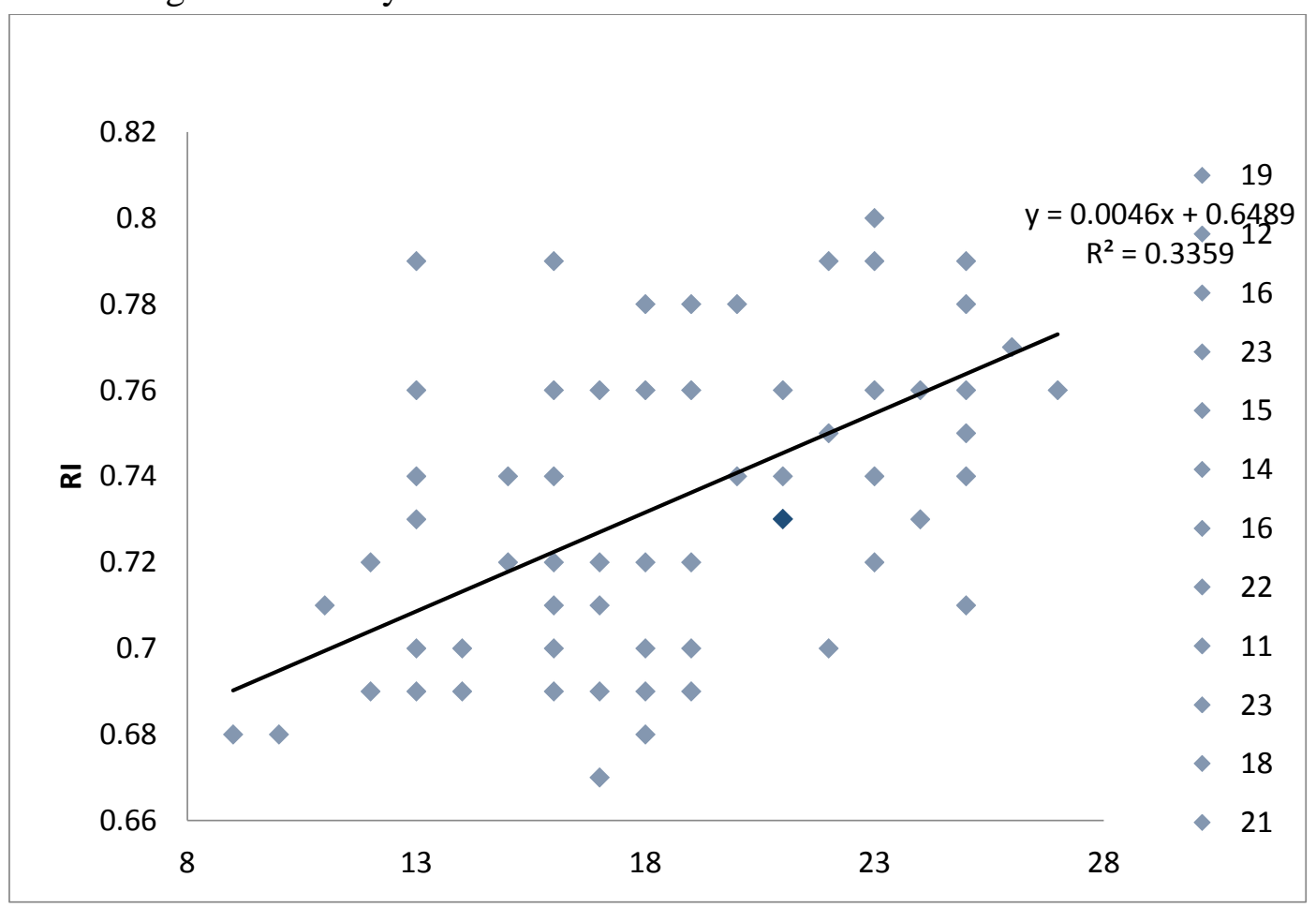


TABLE 4: Pearson Correlation between RI nd MELD

\begin{tabular}{|l|l|}
\hline Pearson Correlation & 0.578 \\
\hline $\mathrm{P}$ value & $<0.001$ \\
\hline $\mathrm{N}$ & 100 \\
\hline
\end{tabular}

\section{DISCUSSION}

Development of hepatorenal syndrome in cirrhosis has so many clinical implications in the course of their disease as they carry a poor prognosis. Diagnosis of HRS needs a very high index of suspicion in cirrhotic patients.

Cirrhotic patients with elevated RIs have impaired short and long term survival and are at risk of developing HRS. Liver cirrhosis is characterized by changes in systemic hemodynamics that lead to renal dysfunction which frequently complicates the clinical course of this disease. ${ }^{8}$ Doppler ultrasound measurement of intrarenal resistance can quantify renal blood flow and it directly correlates with portal pressure. ${ }^{9,10}$ Studies have shown that renal RIs are significantly increased in cirrhotic patients as compared with the healthy controls and are also higher in patients with ascites than in patients without ascites. Patients with decompensated liver disease but having normal serum creatinine can already present with elevated RIs. In our study, the RI values are more in patients with ascites and also in patients having elevated portal pressure. The value was higher among patients under CTP class $\mathrm{C}$ and with MELD 20-29 indicating as the severity disease increases RI also increases. There are also various studies demonstrating that the RI is not inferior to the MELD score in terms of sensitivity and specificity. At the present scenario, the MELD score is used mainly in the transplantation .$^{11}$ but this also indicates the severity of liver disease. It is based on measured variables that include prothrombin time, serum bilirubin and creatinine. $^{12,13}$ Serum creatinine is a major indicator of impaired renal function; but it has disadvantages as it depends more on muscle mass and physical activity. ${ }^{95}$ Therefore, renal function based only on the value of serum creatinine can be overestimated in patients with end stage cirrhosis as they have poor muscle mass. ${ }^{96}$ Thus, it is still necessary to develop improved prognostic markers feasible in daily practice.

\section{CONCLUSION}

From our study we confirm that the value of RI which is based on sonographic measurements of intrarenal resistance is anon-invasive, economical test that gives useful information and it is used as a prognostic indicator and hence used in the management of cirrhotic patients. Elevated RIs even disclose the progress of liver disease before there are gross changes occurring in lab results. Therefore, RI may help in identifying a group of high-risk patients with poor prognosis who require special therapeutic care. ${ }^{16}$ According to the practice guidelines, cirrhotic undergo ultrasound examination every 6-12 months. Along with ultrasound screening of all cirrhotic patients especially with ascites and PHT to estimate the value of RRI by Doppler ultrasound is essentially important as the degree of intrarenal vasoconstriction can be predicted early before overt HRS develops and so preventive measures should be undertaken.

\section{REFERENCES}

1. Bell H, Jahnsen J, Kittang E, Raknerud N, Sandvik L: Long-term prognosis of patients with alcoholic liver cirrhosis: a 15-year follow-up study of 100 Norwegian patients admitted to one unit. Scand J Gastroenterol

2. Gines A, Escorsell A, Gines $\mathrm{P}$ et al. Incidence, predictivefactors, and prognosis of the hepatorenal syndrome incirrhosis with ascites . Gastroenterology $1993 ; 105$ : $229-236$.

3. Ginès A, Escorsell A, Ginès $\mathrm{P}$, Salo J, Jiménez W, Inglada L, Navasa M, Claria J, 
Rimola A, Arroyo V, Rodés J: Incidence, predictive factors and prognosis of the hepatorenal syndrome. Gastroenterology 1993;105:229-236.

4. Arroyo V, Fernandez J, Gin?s P: Pathogen esis and treatment of hepatorenal syndrome. Semin Liver Dis 2008; 28:8195

5. Zeller T, Bonvini RF, Sixt S: Color-coded duplex ultrasound for diagnosis of renal artery stenosis and as follow-up examination after revascularization. Catheter Cardiovasc Interv 2008;71:995-999.

6. Chudek J, Kolonko A, Krol R, Ziaja J, Cierpka L, Wiecek A: The intrarenal vascular resistance parameters measured by duplex Doppler ultrasound shortly after kidney transplantation in patients with immediate, slow, and delayed graft function

7. Götzberger $\mathrm{M}$, Kaiser $\mathrm{C}$, Landauer $\mathrm{N}$, Dieterle C, Heldwein W, Schiemann U: Intrarenal resistance index for the assessment of early renal function impairment in patients with liver cirrhosis. Eur J Med Res 2008;13: 383-387. 11

8. Sacerdoti A, Bolognesi M, Merkel C, Angeli P, Gatta A: Renal vasoconstriction in cirrhosis evaluated by duplex Doppler ultrasonography. Hepatology 1993; 17: 219-224 12

9. Colli A, Cocciolo M, Riva C, Martinez E: Abnormal renovascular impedance in patients with hepatic cirrhosis: detection with duplex US. Radiologie1993;187:561563.13

10. Celebi H, Dönder E, Celiker H: Renal blood flow detection with Doppler Ultrasonography in patients with hepatic cirrhosis. Arch Intern Med 1997;157:564567
11. Kamath PS, Wiesner RH, Malinchoc M, Kremers W, Therneau TM, Kosberg CL, D'Amico G, Dickson ER, Kim WR (2001). "A model to predict survival in patients with end-stage liver disease". Hepatology 33 (2): 464-70.

12. Kamath PS, Kim WR (March 2007). "The model for end-stage liver disease (MELD)". Hepatology 45 (3):

13. Wiesner et al. Model for end-stage liver disease (MELD) and allocation of donor livers. Gastroenterology (2003) vol. 124 (1) pp. 91-6

14. M. A. Papadakis and A. I. Arieff, "Unpredictability of clinical evaluation of renal function in cirrhosis. Prospective study," The American Journal of Medicine, vol 82, no 5, pp 945-952, 1987.

15. L. Caregaro, F. Menon, P. Angeli et al., "Limitations of serum creatinine level and creatini.ne clearance as filtration markers in cirrhosis," Archives of Internal Medicine, vol. 154, no. 2, pp. 201-205, 1994.

16. Radermacher J, Ellis S, Haller H. Renal resistance index and progression of renal disease. Hypertension 2002; 39:699-703.
ABBREVATIONS USED:
HRS : HEPATORENAL SYNDROME
RI : RESISTIVE INDEX
MELD: MODEL FOR END-STAGE LIVER DISEASE
INR:INTERNATIONAL NORMALIZED RATIO CTP : CHILD-TURCOTTE-PUGH SCORE PHT : PULMONARY HYPERTENSION PSV : PEAK SYSTOLIC VELOCITY EDV : END DIASTOLIC VOLUME 